Check for updates

Cite this: RSC Adv., 2017, 7, 30032

\title{
Flower-like carbon with embedded silicon nano particles as an anode material for Li-ion batteries $\uparrow$
}

\author{
Hui Zhang, ${ }^{\text {abd }}$ Hui Xu, ${ }^{\text {abd }}$ Hong Jin, ${ }^{\text {abd }}$ Chao Li, ${ }^{\text {bd }}$ Yu Bai ${ }^{\star a b d}$ and Kun Lian (D) *abcd
}

A novel 3-dimensional (3D) flower-like silicon/carbon composite was synthesized through spray drying method by using $\mathrm{NaCl}$ as the sacrificial reagent and was evaluated as an anode material for lithium ion batteries. This composite is composed of silicon nanoparticles distributed in the flower-like carbon framework. Cycling test results showed that, serving as the anode material, the composite achieved excellent capacity values of $1323 \mathrm{~mA} \mathrm{~h} \mathrm{~g}^{-1}$ at $\mathrm{C} / 20\left(1 \mathrm{C}=4200 \mathrm{~mA} \mathrm{~g}^{-1}\right)$ after 100 cycles and $985 \mathrm{~mA} \mathrm{~h}$ $\mathrm{g}^{-1}$ at $\mathrm{C} / 2$ after 200 cycles, respectively. The enhancement of electrode stability, compared to the conventional silicon anode made of bare silicon nano particles, is attributed to the unique flower-like 3D structure of the composite, which helps to maintain the mechanical stability of the electrode, and therefore maintains better electrical contact between the anode material and the current collector.

Received 28th March 2017

Accepted 21st May 2017

DOI: $10.1039 / \mathrm{c} 7 \mathrm{ra03576d}$

rsc.li/rsc-advances

result in constant consumption of the liquid electrolyte when they are exposed to the electrolyte directly and sequentially the formation of thick solid electrolyte interphase (SEI). ${ }^{21,22}$ Thus a stable isolation layer around SiNPs is needed to buffer their volume change and to avoid directly contact with the electrolyte. Different forms of carbon materials have already been widely used in LIBs both in industry and in latest academic researches. Carbon is an ideal isolation material because of its excellent chemical stability, mechanical strength, electrical conductivity and ion transmission capability. In addition, carbon and silicon are both group IV materials and have good compatibility to each other. Therefore, compositing with carbon has been widely adopted to overcome the disadvantage of silicon anode and to improve the electrochemical performances of the electrode, such as cycling stability and rate capacity.

Besides material selection, architectural design is another efficient way to address materials challenges in electrodes of energy storage systems such as LIB and supercapacitor, especially for composite electrode materials. ${ }^{23}$ For example, promising approaches to optimize the $\mathrm{Si} / \mathrm{C}$ composite anode include but not limited to the following: creating a core-shell structured composite to prevent SiNPs from being exposed to electrolyte by encapsulating SiNPs in the carbon shell, ${ }^{22,24-28}$ and embedding SiNPs in porous carbon to accommodate its volume expansion by void space in the carbon framework. For the latter method, the 3D porous nanostructure also avails fast ion transport by increasing the surface area contacting the electrolyte. To create a 3D porous nanostructure, a variety of inactive materials named sacrificial reagent have been widely exploited which play a structural buffering role to minimize the mechanical stress induced by the huge volume change of silicon, therefore prevent the deterioration of the electrode integrity. ${ }^{2} \mathrm{SiO}_{2}$ is an ordinary sacrificial reagent used to construct void space structure. For 
example, Yi $\mathrm{Cui}^{3}$ et al. fabricated pomegranate-like $\mathrm{Si} / \mathrm{C}$ composite microspheres by etching the $\mathrm{SiO}_{2}$ around SiNPs with $\mathrm{HF}$ to form a void space structure. Numerous research groups have investigated $\mathrm{Si}^{14}$ or $\mathrm{SiO}_{2}$ (ref. 29) as well as $\mathrm{SiO}_{x}$ (ref. 19) as the sacrificial reagents that have to be removed by using HF, which is toxic and corrosive. ${ }^{18,19,30}$ Given that, it's desired to find a new environmentally friendly sacrificial reagent that can be removed relatively easily to construct a void $\mathrm{Si} / \mathrm{C}$ structure for high cycling performance anode.

In this work, spray drying technique is applied to fabricate the $\mathrm{Si} / \mathrm{C}$ composite for its low cost, simple preparation processes and scaling capability. Salt $(\mathrm{NaCl})$ has been used as the sacrificial reagents to form a flower-like carbon framework embedded with SiNPs. The SiNPs are well supported by the carbon framework and form good contact with the current collector during charge and discharge. As a result, this flowerlike silicon/carbon (F-Si/C) composite has exhibited superior performance during the cycling test, showing a stable capacity value of above $1323 \mathrm{~mA} \mathrm{~h} \mathrm{~g}^{-1}$ (at $\mathrm{C} / 20$ ) up to 100 cycles with good rate performance. As sacrificial reagent, $\mathrm{NaCl}$ can be easily removed by immersing in DI water, which is convenient and environmentally friendly. Through spray drying method, the porous carbon framework can be fabricated using different sacrificial reagents, making it applicable to fabricate other anode materials which also suffer volume change problems, such as $\mathrm{Sn}, \mathrm{Sb}, \mathrm{Mg}, \mathrm{Al}$, etc.

The process of synthesis of flower-like $\mathrm{Si} / \mathrm{C} \quad(\mathrm{F}-\mathrm{Si} / \mathrm{C})$ composite is illustrated in Fig. 1, and the probable steps for the formation process of the $\mathrm{F}-\mathrm{Si} / \mathrm{C}$ composite are proposed in the ESI part. $\dagger$ During the preparation process, though 6 hours of stirring, the mixture consisting of SiNPs, $\mathrm{NaCl}$, and PVP were thoroughly blended. After being carbonized at $900{ }^{\circ} \mathrm{C}$, the flower-like structure forms when $\mathrm{NaCl}$ nano crystals were removed by rinsing in deionized water, which can be seen in Fig. $2(\mathrm{a}-\mathrm{c})$. The $\mathrm{F}-\mathrm{Si} / \mathrm{C}$ particles are about $3-5 \mu \mathrm{m}$ in size with numerous carbon petals embedded with SiNPs. In order to investigate the formation process of $\mathrm{F}-\mathrm{Si} / \mathrm{C}$ particles, intermediate products during the synthesis process were also observed with SEM. During the following carbonization process, PVP reagents in these particles was carbonized and $\mathrm{NaCl}$ nano crystals were exposed (Fig. 2(d)). In addition, as shown by EDX mapping in Fig. 2(e), $\mathrm{Na}, \mathrm{Cl}$ and $\mathrm{Si}$ elements were evenly distributed inside the carbon framework. In order to verify the role $\mathrm{NaCl}$ played as the sacrificial reagents in forming the flower-like microstructures, we carried out a contrasting experiment. In this experiment, the same process as above was followed except for not using $\mathrm{NaCl}$ as the sacrifice reagents, and a sphere-like $\mathrm{Si} / \mathrm{C}$ composite (S-Si/C) was obtained. The size of $\mathrm{S}-\mathrm{Si} / \mathrm{C}$ particles is around $3-5 \mu \mathrm{m}$ as Fig. $2(\mathrm{f})$ and (g) shows. These $\mathrm{S}-\mathrm{Si} / \mathrm{C}$ particles appear to be denser, with much less gullies or voids, and less interconnected compared to the F-Si/C particles. The specific surface area of $\mathrm{F}-\mathrm{Si} / \mathrm{C}$ and $\mathrm{S}-\mathrm{Si} / \mathrm{C}$ composites was analyzed by $\mathrm{N}_{2}$ gas adsorption-desorption measurements (Fig. S2 $\dagger$ ). BET analysis indicated that the specific surface area of F-Si/C composite was up to $173 \mathrm{~m}^{2} \mathrm{~g}^{-1}$, which is much higher than the specific surface area of S-Si/C composite $\left(\sim 14 \mathrm{~m}^{2} \mathrm{~g}^{-1}\right)$. Comparing the two types of $\mathrm{Si} / \mathrm{C}$ particles, we can see that during the synthesis process, $\mathrm{NaCl}$ plays an important role as sacrifice reagent, embedding in the carbon framework and forming voids after being removed. As a result, surface area of the $\mathrm{F}-\mathrm{Si} / \mathrm{C}$ composite are greatly increased comparing to the $\mathrm{S}-\mathrm{Si} / \mathrm{C}$ composite. The advantages of using $\mathrm{NaCl}$ as sacrifice reagent are as following: (a) it is easier to remove than other sacrifice reagents like $\mathrm{SiO}_{2}$ or Ni which are common used. ${ }^{3,31}$ (b) During the synthesis process, $\mathrm{NaCl}$ is randomly distributed in the microstructure and not just formed on the surface of SiNPs, leading to void spaces evenly distributed in the framework of the final $\mathrm{F}-\mathrm{Si} / \mathrm{C}$ composite. The advantage of this structure is that the carbon framework is much more stable during the charging and discharging process, because the void space in the framework could effectively release the stress caused by the volume change of the SiNPs. (c) The synthesis process is simple and environmentally friendly. The spray drying process has been commonly used for a wide range of industrial products. All reagents used are innocuous, commercially available, and low cost.

The chemical compositions of the F-Si/C composite during and after the synthesis process were further confirmed using Xray diffraction (XRD). As shown in Fig. 2(h), all major diffraction peaks are indexed to cubic $\mathrm{Si}$ (JCPDS card no. 27-1402) and $\mathrm{NaCl}$ (JCPDS card no. 05-0628) before removing the sacrifice reagents, which indicates that the crystal type of the SiNPs were not affected by spray drying, annealing and washing. Furthermore, no peaks corresponding to $\mathrm{SiO}_{2}$ or $\mathrm{SiC}$ were detected from the XRD pattern, which indicates that the SiNPs were protected from oxidation by this unique structure during the whole synthesis process of $\mathrm{F}-\mathrm{Si} / \mathrm{C}$ composite. XRD pattern of the raw SiNPs is also provided in Fig. 2(h) for comparison.

The micro-structure of the $\mathrm{F}-\mathrm{Si} / \mathrm{C}$ composite was further characterized by TEM (Fig. 3). It is clear that the SiNPs are randomly distributed inside or semi-embed in the carbon framework. It can also be seen that the SiNPs are less than

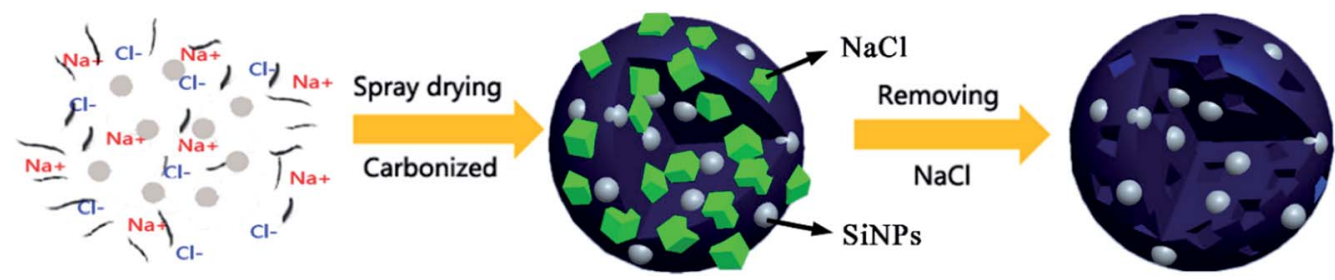

Fig. 1 Schematic illustration of the synthesis process of the F-Si/C composite. 

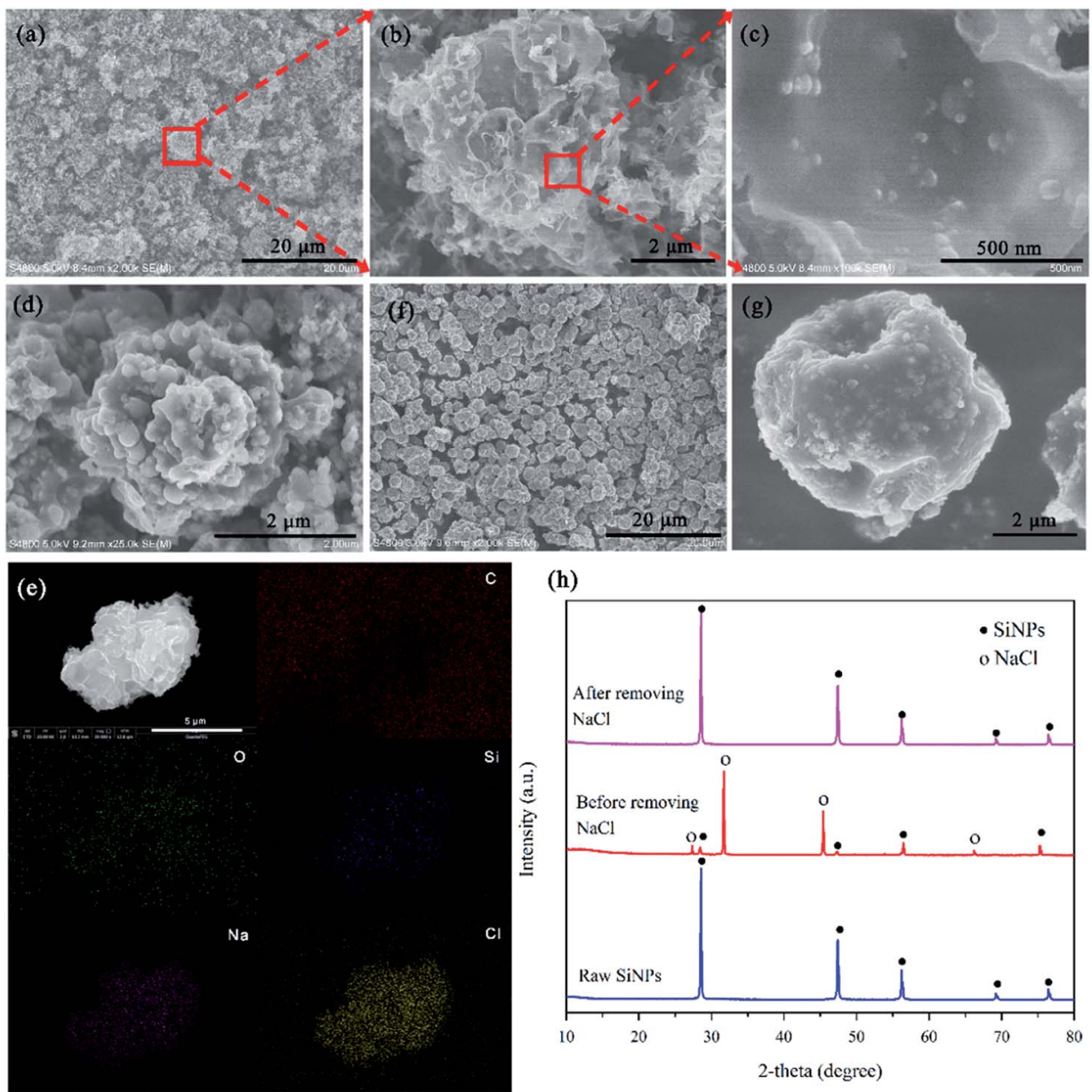

(h)

Fig. 2 (a-c) SEM images of F-Si/C composite at different magnifications; (d) the SEM of F-Si/C composite after being carbonized without removing $\mathrm{NaCl}$ reagents; (e and f) SEM images of S-Si/C composite. (g) Images of EDX mapping of $\mathrm{F}-\mathrm{Si} / \mathrm{C}$ composite after being carbonized before removing $\mathrm{NaCl}$ reagents. It can be seen that $\mathrm{C}, \mathrm{O}, \mathrm{Si}, \mathrm{Na}$, and $\mathrm{Cl}$ all distribute evenly in the composite. The oxygen and carbon backgrounds around the particle are from conducting tape consisting of oxygen and carbon. (h) XRD patterns of raw SiNPs, and F-Si/C composite before and after removing $\mathrm{NaCl}$ reagents.

$100 \mathrm{~nm}$ in size, which is in agreement with the bare SiNPs we used $(D<100 \mathrm{~nm})$.

The cycling performances of the bare electrodes made of SiNPs, $\mathrm{F}-\mathrm{Si} / \mathrm{C}$ and $\mathrm{S}-\mathrm{Si} / \mathrm{C}$ composites at a rate of $\mathrm{C} / 2$ with voltages from 0.02 to $1 \mathrm{~V}$ are shown in Fig. $4(\mathrm{a})$. It is noted that the bare SiNPs electrode exhibites a poor cycling performance. The
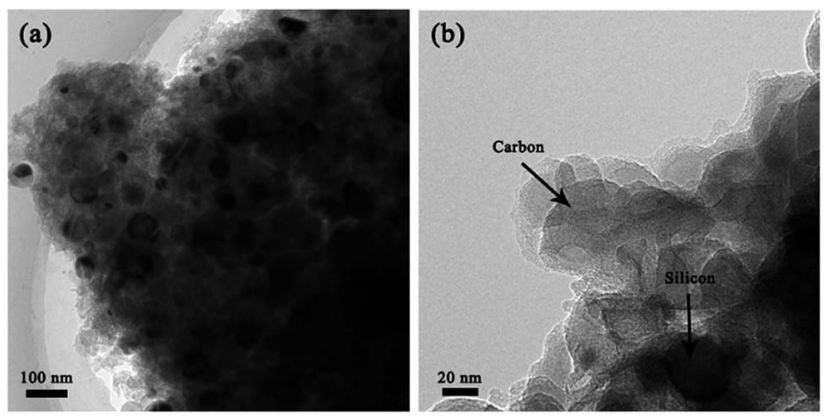

Fig. 3 TEM images of $\mathrm{F}-\mathrm{Si} / \mathrm{C}$ composite at different magnifications. capacity of the bare SiNPs electrode decreases rapidly from an initial capacity of $3810 \mathrm{~mA} \mathrm{~h} \mathrm{~g}^{-1}$ (not shown in figure) to 128 $\mathrm{mA} \mathrm{h} \mathrm{g}^{-1}$ after only a few cycles. It's reported that when normal SiNPs are exposed to the electrolyte, the SEI film would rupture and form repeatedly on the surface of the bare SiNPs due to the large volume expansion and contraction during lithium and delithium cycling. ${ }^{13,32}$ Since the SEI film is an electronic insulator, eventually, the SEI film with ever increasing thickness would prevent the lithium ions from being transferred to the surface of bare SiNPs. ${ }^{1,33,34}$ Moreover, the repeated volume change results in the loss of electrical contact between bare SiNPs and binder..$^{35,36}$ Compared with the bare SiNPs electrode, both the $\mathrm{S}-\mathrm{Si} / \mathrm{C}$ electrode and $\mathrm{F}-\mathrm{Si} / \mathrm{C}$ electrode shows a much higher capacity initially and $\mathrm{F}-\mathrm{Si} / \mathrm{C}$ electrode also shows excellent cycling stability. The reversible capacity of $\mathrm{F}-\mathrm{Si} / \mathrm{C}$ electrode gradually drops from $1143 \mathrm{~mA} \mathrm{~h} \mathrm{~g}^{-1}$ at the initial cycle to 898 $\mathrm{mA} \mathrm{h} \mathrm{g}{ }^{-1}$ after 200 cycles, showing $79 \%$ of capacity retention. Coulombic efficiency (CE) of the $\mathrm{F}-\mathrm{Si} / \mathrm{C}$ electrode is $53 \%$ at the initial cycle, but rapidly increases to $98 \%$ at the $5^{\text {th }}$ cycle, and then gradually stabilizes at $\sim 99 \%$. In comparision, the capacity 

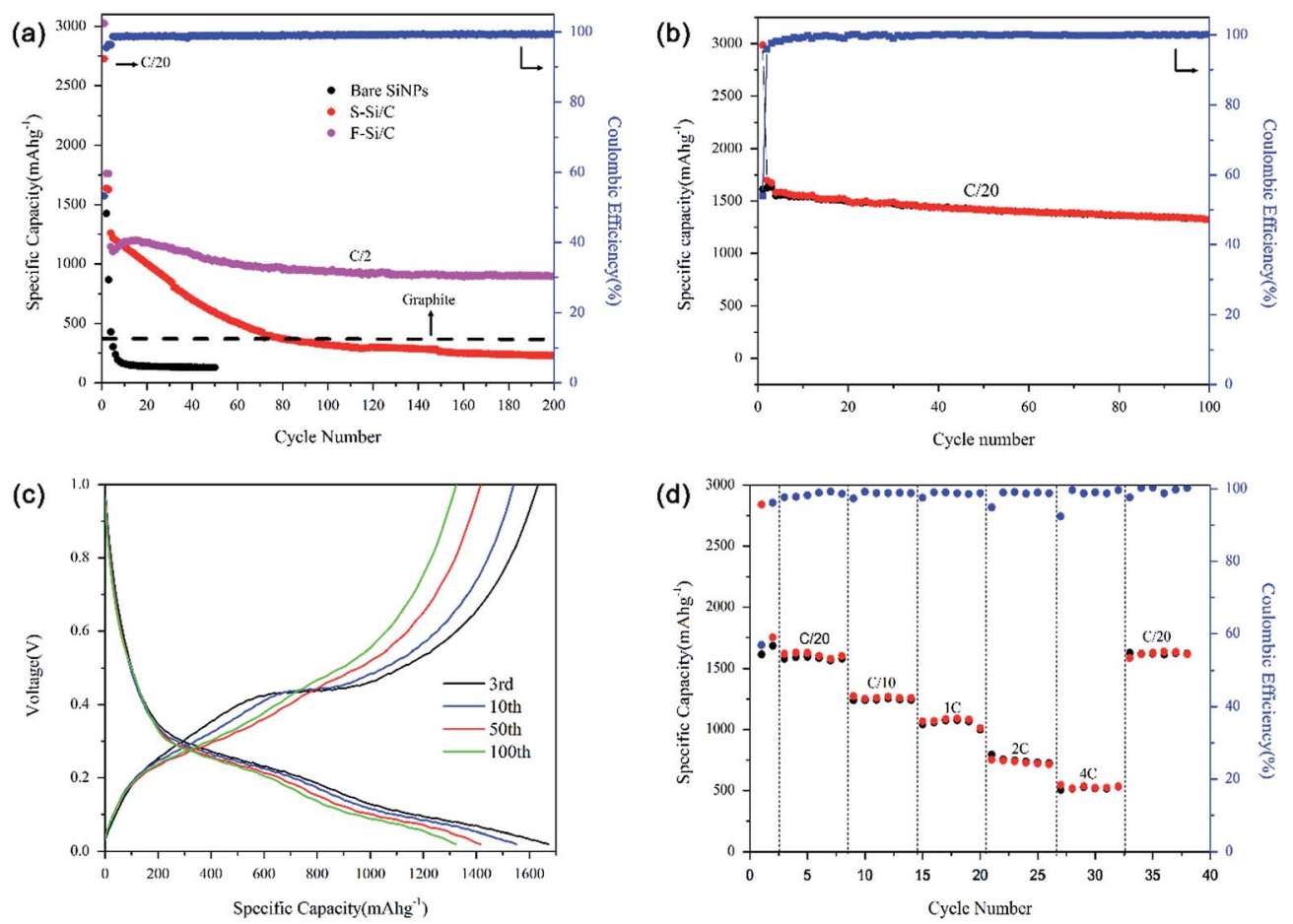

Fig. 4 Electrochemical performance of F-Si/C electrode. (a) Cycling performance of $\mathrm{F}-\mathrm{Si} / \mathrm{C}$ electrode, $\mathrm{S}-\mathrm{Si} / \mathrm{C}$ electrode, and bare SiNPs electrode measured at $\mathrm{C} / 2\left(1 \mathrm{C}=4200 \mathrm{~mA} \mathrm{~g}^{-1}\right)$. (b) Cycling performance of $\mathrm{F}-\mathrm{Si} / \mathrm{C}$ electrode at $\mathrm{C} / 20$ rate. (c) Galvanostatic charge-discharge characteristics of $\mathrm{F}-\mathrm{Si} / \mathrm{C}$ electrode for the $3 \mathrm{rd}, 10 \mathrm{th}, 50$ th, and 100th cycles at rate of C/20. (d) Charge/discharge capacity of F-Si/C electrode at various rates from $\mathrm{C} / 20$ to $4 \mathrm{C}$ as well as the coulombic efficiency.

of the $\mathrm{S}-\mathrm{Si} / \mathrm{C}$ electrode decrease to $257 \mathrm{~mA} \mathrm{~h}^{-1}$ after 200 cycles ( $23 \%$ of capacity retention) which is lower than the graphite capacity of $374 \mathrm{~mA} \mathrm{~h} \mathrm{~g}^{-1}$ (the dot line in Fig. 4(a)). The significant improvement in cycling performance of the $\mathrm{F}-\mathrm{Si} / \mathrm{C}$ electrode suggests that the $\mathrm{F}-\mathrm{Si} / \mathrm{C}$ composite can maintain a stable structure during cycling. For the flower-like carbon framework, void spaces can accommodate the large volume expansion of SiNPs upon lithiation without breaking the carbon framework, and the carbon framework is able to enhance the conductivity between SiNPs. Futhermore, the compact carbon framework can prevent the electrolyte from penetrating into the internal of carbon, as well as protect the carbon framework against destruction during the process of electrode fabrication. The total content of SiNPs in the composite also has influence on the electrochemical performance, which is discussed in the ESI part (Fig. S4-S6†).

Fig. 4(b) shows that at 100 cycles, the capacity of $\mathrm{F}-\mathrm{Si} / \mathrm{C}$ electrode keeps stable at $1323 \mathrm{~mA} \mathrm{~h} \mathrm{~g}^{-1}$ at the rate of $\mathrm{C} / 20$ and the $\mathrm{CE}$ is around $99.6 \%$ even though the capacity decreased slightly. This improvement of the specific capacity and cycle life demonstrates the advantages of the $\mathrm{F}-\mathrm{Si} / \mathrm{C}$ anode design. The voltage profiles of $\mathrm{F}-\mathrm{Si} / \mathrm{C}$ electrodes exhibited typical electrochemical features of $\mathrm{Si}$, with little change after 100 cycles, which can be seen in Fig. 4(c). Coulombic efficiency is an indicator of the reversibility of the electrode reaction. SEI rupture and reformation usually results in decreased coulombic efficiency, especially in later cycles. ${ }^{37}$ The average $\mathrm{CE}$ from $3^{\text {rd }}$ to $100^{\text {th }}$ cycles of the $\mathrm{F}-\mathrm{Si} / \mathrm{C}$ electrode is as high as $99.66 \%$. To further evaluate the potential of $\mathrm{F}-\mathrm{Si} / \mathrm{C}$ electrodes, charge and discharge cycling tests were performed under various rates of $\mathrm{C} /$ 20, C/10, 1C, 2C, 4C. The results are plotted in Fig. 4(d). The capacities at these rates were measured to be $1592 \mathrm{~mA} \mathrm{~h} \mathrm{~g}^{-1}$, $1243 \mathrm{~mA} \mathrm{~h} \mathrm{~g}^{-1}, 998 \mathrm{~mA} \mathrm{~h} \mathrm{~g}^{-1}, 724 \mathrm{~mA} \mathrm{~h} \mathrm{~g}^{-1}, 531 \mathrm{~mA} \mathrm{~h} \mathrm{~g}^{-1}$, respectively; even when charge rate increased 20 -times from $\mathrm{C} /$ 20 to $1 \mathrm{C}$, the $\mathrm{F}-\mathrm{Si} / \mathrm{C}$ electrode maintained $\sim 63 \%$ of its initial capacity; it still preserved $\sim 32 \%$ of its initial capacity at $4 \mathrm{C}$, which is $\sim 1.5$ times of a graphite anode $\left(372 \mathrm{~mA} \mathrm{~h} \mathrm{~g}^{-1}\right)$. When the rate is returned to $\mathrm{C} / 20$ after a total of 38 cycles, a capacity of $1622 \mathrm{~mA} \mathrm{~h} \mathrm{~g}^{-1}$ was still recoverable, suggesting a very stable structure of the $\mathrm{F}-\mathrm{Si} / \mathrm{C}$ electrode even under high rate cycling.

$\mathrm{CV}$ profiles of the $\mathrm{F}-\mathrm{Si} / \mathrm{C}$ electrode were measured to clarify the kinetic behaviour and stability during cycling, as shown in Fig. 5(a). As observed, one cathodic peaks centered at $0.8 \mathrm{~V}$ are observed in first cycle but disappeared in the subsequent cycles. This is mainly attributed to the irreversible reactions between the carbon framework and electrolyte to form the SEI layer. ${ }^{22}$ The characteristic pair (cathodic, anodic) of current peaks (at $0.21 \mathrm{~V}, 0.32 \mathrm{~V}, 0.47 \mathrm{~V}$ ) could be attributed to the lithiuminsertion/extraction processes. It should be noted that the cathodic peaks located at $0.21 \mathrm{~V}$ become more distinct during cycling because of the gradual evolution from crystalline Si to amorphous $\mathrm{Si}$ with repeated lithium-insertion/extraction process. ${ }^{25}$ Additionally, the intensity of anodic peaks at $0.32 \mathrm{~V}$ and $0.47 \mathrm{~V}$ increase gradually in the initial three cycles, suggesting the existence of polarization processes in the $\mathrm{F}-\mathrm{Si} / \mathrm{C}$ electrode. 

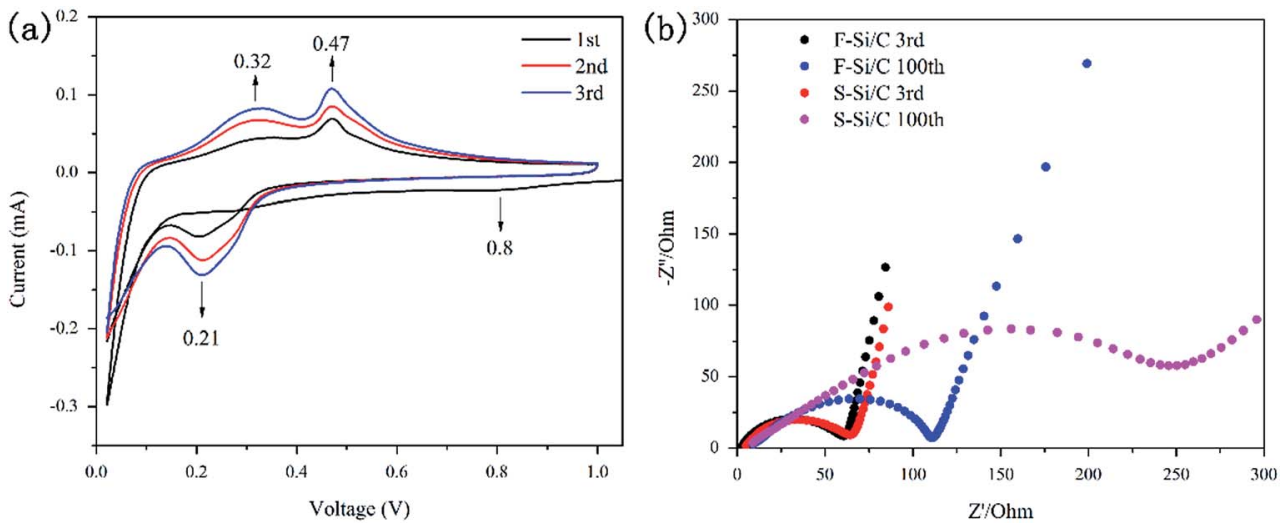

Fig. 5 (a) Cyclic voltammetry curves of the $\mathrm{F}-\mathrm{Si} / \mathrm{C}$ electrode in the potential window between $0.02 \mathrm{~V}$ to $1 \mathrm{~V}$ at the rate of $0.005 \mathrm{mV} \mathrm{s}{ }^{-1}$. (b) Nyquist plots of the cells with $\mathrm{F}-\mathrm{Si} / \mathrm{C}$ and $\mathrm{S}-\mathrm{Si} / \mathrm{C}$ electrodes at $3 \mathrm{rd}$ and 100 th cycles.
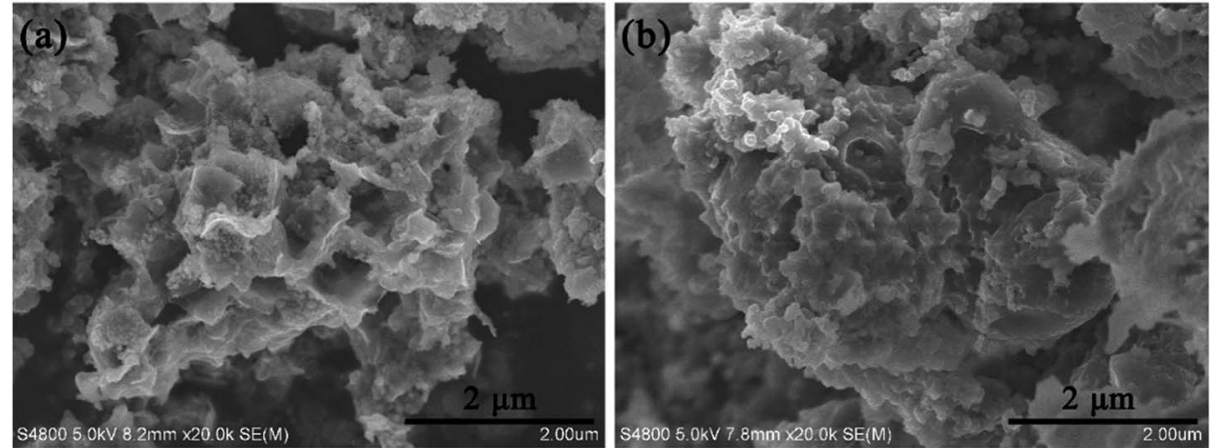

Fig. 6 SEM of (a) F-Si/C and (b) S-Si/C electrode after 100 cycles.

The change in the impedance of the $\mathrm{F}-\mathrm{Si} / \mathrm{C}$ and $\mathrm{S}-\mathrm{Si} / \mathrm{C}$ electrodes during cycling tests were determined by EIS measurements (Fig. 5(b)). The semicircle in the high-frequency range of Nyquist plots is attributed to a charge-transfer phenomenon. ${ }^{38}$ It is noted that the diameters of the semicircle of $\mathrm{F}-\mathrm{Si} / \mathrm{C}$ and $\mathrm{S}-\mathrm{Si} / \mathrm{C}$ electrodes are almost same in the 3rd cycle (about $65 \Omega$ ). It is also noted that the enhancement of $\mathrm{S}-\mathrm{Si}$ / C electrode is up to $290 \Omega$ after 100th cycles while the F-Si/C electrode increases to $110 \Omega$ suggesting an increasing of charge transfer resistance $\left(R_{\mathrm{ct}}\right)$. This result testifies for the advantages of the "flower-like" structure. It can be explained that a comparably stable SEI was formed on the surface of the F$\mathrm{Si} / \mathrm{C}$ electrode while a thicker and thicker SEI was developed on $\mathrm{S}-\mathrm{Si} / \mathrm{C}$ electrode. With the cycles continuing, the expandation of SiNPs destroys the structure of the S-Si/C electrode, which was effectively avoided by the $\mathrm{F}-\mathrm{Si} / \mathrm{C}$ composite structure.

In order to understand the mechanism for the much higher performance of the $\mathrm{F}-\mathrm{Si} / \mathrm{C}$ composite than the $\mathrm{S}-\mathrm{Si} / \mathrm{C}$ composite, the cells of $\mathrm{F}-\mathrm{Si} / \mathrm{C}$ and $\mathrm{S}-\mathrm{Si} / \mathrm{C}$ electrodes were disassembled after 100 discharge/charge cycles in fully delithiation condition. For the F-Si/C electrode, as shown in Fig. 6(a), the overall flower-like structure is maintained. Although not as clearly defined as freshly prepared due to the SEI formation and the volume change of $\mathrm{Si}$, SiNPs can still be seen as embedded in the outer surface of the carbon petals. On the other hand, for the S-Si/C electrode, comparing Fig. 6(b) with Fig. 2(f), one can see that the spherical structure was fractured into smaller piece, losing structural integrity, which we believe it is due to the expandation of SiNPs during the cycling. In addition, we believe that for the S-Si/C structure, the SEI would form outside of the carbon micro particles, leading to a low ionic conductivity. Therefore, the battery fails quickly after several cycles.

From the above analysis, we can conclude that the flower-like structure made by using $\mathrm{NaCl}$ sacrifice reagents is beneficial to maintain the structural stability of the composite electrode. The flower-like structure can accommodate the dramatic deformation processed that occur when SiNPs are loaded with Li-ion, maintain good structural stability, good electronic and ionic conduction pathways, which results in excellent cycling performance.

\section{Conclusions}

A flower-like $\mathrm{Si} / \mathrm{C}$ (F-Si/C) was synthesized using the method of spray drying with the environmentally friendly and low-cost $\mathrm{NaCl}$ as sacrifice reagents. The $\mathrm{F}-\mathrm{Si} / \mathrm{C}$ electrode exhibited a high reversible capacity of $1323 \mathrm{~mA} \mathrm{~h} \mathrm{~g}^{-1}$ after 100 cycles at a C/20 rate. Compared with SiNPs and the sphere-like Si/C, the $\mathrm{F}-\mathrm{Si} / \mathrm{C}$ electrode had the best combination of reversible capacity and cycling stability. The excellent cycling performance of $\mathrm{F}-\mathrm{Si} /$ 
C was attributed to the special flower-like structure which is SiNPs embedded in the carbon framework with partial void spaces that accommodates the volume expansion. This low cost, easy-to-use synthesize method may also be useful for other materials that suffers from volume change during electrochemical reactions.

\section{Acknowledgements}

This work is sponsored by the Collaborative Innovation Center of Suzhou Nano Science and Technology, Jiangsu Province Department of Science and Technology international science and technology cooperation project (BZ2015035), Jiangsu Province Fundamental Research Grant (BK20130368, BK20131184, BK20150379, BK20160389), Key Laboratory of Renewable Nanomaterials of Suzhou (SZS201513). Suzhou City Key Industry Technological Innovation (Perspective Application Research) Grant (SYG201621).

\section{Notes and references}

1 T. Wada, T. Ichitsubo, K. Yubuta, H. Segawa, H. Yoshida and H. Kato, Nano Lett., 2014, 14, 4505-4510.

$2 \mathrm{H}$. Wu and Y. Cui, Nano Today, 2012, 7, 414-429.

3 N. Liu, Z. Lu, J. Zhao, M. T. McDowell, H. W. Lee, W. Zhao and Y. Cui, Nat. Nanotechnol., 2014, 9, 187-192.

4 X. H. Liu, L. Zhong, S. Huang, S. X. Mao, T. Zhu and J. Y. Huang, ACS Nano, 2012, 6, 1522-1531.

5 J. W. Liang, X. N. Li, Y. C. Zhu, C. Guo and Y. T. Qian, Nano Res., 2015, 8, 1497-1504.

6 A. Magasinski, P. Dixon, B. Hertzberg, A. Kvit, J. Ayala and G. Yushin, Nat. Mater., 2010, 9, 353-358.

7 M. Wu, J. E. Sabisch, X. Song, A. M. Minor, V. S. Battaglia and G. Liu, Nano Lett., 2013, 13, 5397-5402.

8 C. K. Chan, H. Peng, G. Liu, K. McIlwrath, X. F. Zhang, R. A. Huggins and Y. Cui, Nat. Nanotechnol., 2008, 3, 31-35.

9 Q. Wu, T. Tran, W. Lu and J. Wu, J. Power Sources, 2014, 258, 39-45.

10 A. A. Benjamin Hertzberg and G. Yushin, J. Am. Chem. Soc., 2010, 132, 8548-8549.

11 J. H. Cho and S. T. Picraux, Nano Lett., 2014, 14, 3088-3095. 12 K. Karki, E. Epstein, J. H. Cho, Z. Jia, T. Li, S. T. Picraux, C. Wang and J. Cumings, Nano Lett., 2012, 12, 1392-1397.

13 T. Song, J. Xia, J. H. Lee, D. H. Lee, M. S. Kwon, J. M. Choi, J. Wu, S. K. Doo, H. Chang, W. I. Park, D. S. Zang, H. Kim, Y. Huang, K. C. Hwang, J. A. Rogers and U. Paik, Nano Lett., 2010, 10, 1710-1716.

14 C. L. Pang, H. W. Song, N. Li and C. X. Wang, RSC Adv., 2015, 5, 6782-6789.

15 Y. Yao, M. T. McDowell, I. Ryu, H. Wu, N. Liu, L. Hu, W. D. Nix and Y. Cui, Nano Lett., 2011, 11, 2949-2954.
$16 \mathrm{~J}$. Zhu and D. Deng, RSC Adv., 2015, 5, 67315-67322.

17 N. Liu, H. Wu, M. T. McDowell, Y. Yao, C. Wang and Y. Cui, Nano Lett., 2012, 12, 3315-3321.

18 S. Choi, D. S. Jung and J. W. Choi, Nano Lett., 2014, 14, 71207125.

19 Y. S. Hu, R. Demir-Cakan, M. M. Titirici, J. O. Muller, R. Schlogl, M. Antonietti and J. Maier, Angew. Chem., 2008, 47, 1645-1649.

20 M. Dirican, Y. Lu, K. Fu, H. Kizil and X. W. Zhang, RSC Adv., 2015, 5, 34744-34751.

21 J. Zhao, Z. Lu, N. Liu, H. W. Lee, M. T. McDowell and Y. Cui, Nat. Commun., 2014, 5, 5088.

22 P. Wu, H. Wang, Y. Tang, Y. Zhou and T. Lu, ACS Appl. Mater. Interfaces, 2014, 6, 3546-3552.

23 Q. Xia, M. Xu, H. Xia and J. Xie, ChemNanoMat, 2016, 2, 588600.

24 H. R. Zhang, X. Y. Qin, J. X. Wu, Y. B. He, H. D. Du, B. H. Li and F. Y. Kang, J. Mater. Chem. A, 2015, 3, 7112-7120.

25 T. H. Hwang, Y. M. Lee, B. S. Kong, J. S. Seo and J. W. Choi, Nano Lett., 2012, 12, 802-807.

26 T. Cetinkaya, M. Uysal, M. O. Guler and H. Akbulut, Int. J. Hydrogen Energy, 2014, 39, 21405-21413.

27 S. H. Ng, J. Wang, D. Wexler, K. Konstantinov, Z. P. Guo and H. K. Liu, Angew. Chem., 2006, 45, 6896-6899.

28 L. F. Cui, R. Ruffo, C. K. Chan, H. Peng and Y. Cui, Nano Lett., 2009, 9, 491-495.

29 D. S. Jung, T. H. Hwang, S. B. Park and J. W. Choi, Nano Lett., 2013, 13, 2092-2097.

$30 \mathrm{H}$. Wu, G. Zheng, N. Liu, T. J. Carney, Y. Yang and Y. Cui, Nano Lett., 2012, 12, 904-909.

31 Y. Li, K. Yan, H.-W. Lee, Z. Lu, N. Liu and Y. Cui, Nat. Energy, 2016, 1, 15029.

32 V. A. Sethuraman, V. Srinivasan and J. Newman, J. Electrochem. Soc., 2012, 160, A394-A403.

33 B. Wang, X. Li, T. Qiu, B. Luo, J. Ning, J. Li, X. Zhang, M. Liang and L. Zhi, Nano Lett., 2013, 13, 5578-5584.

34 A. S. Westover, D. Freudiger, Z. S. Gani, K. Share, L. Oakes, R. E. Carter and C. L. Pint, Nanoscale, 2015, 7, 98-103.

35 H. Yang, S. Huang, X. Huang, F. Fan, W. Liang, X. H. Liu, L. Q. Chen, J. Y. Huang, J. Li, T. Zhu and S. Zhang, Nano Lett., 2012, 12, 1953-1958.

36 Y. Yang, R. Liu, J. Wu, X. Jiang, P. Cao, X. Hu, T. Pan, C. Qiu, J. Yang, Y. Song, D. Wu and Y. Su, Sci. Rep., 2015, 5, 13480.

37 C. Wang, H. Wu, Z. Chen, M. T. McDowell, Y. Cui and Z. Bao, Nat. Chem., 2013, 5, 1042-1048.

38 H. Wu, G. Chan, J. W. Choi, I. Ryu, Y. Yao, M. T. McDowell, S. W. Lee, A. Jackson, Y. Yang, L. Hu and Y. Cui, Nat. Nanotechnol., 2012, 7, 310-315. 